\title{
BILATERAL ORBITAL METASTASES FROM TRANSITIONAL CELL CARCINOMA OF THE BLADDER
}

\author{
C. E. HUGKULSTONE ${ }^{1}$, S. WINDER ${ }^{1}$ and M. SOKAL ${ }^{2}$ \\ Nottingham
}

\begin{abstract}
SUMMARY
A case of bilateral orbital metastases arising from a primary transitional cell carcinoma of the bladder is presented, with simultaneous presentation of both primary and metastatic disease. The literature is reviewed.
\end{abstract}

Metastases to the orbit may present difficulties in both diagnosis and management. Their incidence in reported series of space-occupying orbital lesions is low, accounting for between approximately $2.5 \%^{1-3}$ and $3.5 \%^{4}$ of such lesions. The commonest site of the primary tumour is the breast,,$^{2,5-7}$ and orbital metastases are more common in patients over 60 years of age. ${ }^{1.5}$

To the best of our knowledge, there have been only two previous reports of histologically proven orbital metastases from transitional cell carcinoma (TCC) of the bladder. ${ }^{8.9}$ Both these patients were over 60 years of age, and had unilateral orbital lesions. We report here on a younger patient, who had bilateral orbital metastases from TCC of the bladder, with histological diagnosis of both primary and metastatic lesions.

\section{CASE REPORT}

The patient was a 45-year-old, previously healthy man. He first presented to the Ophthalmic Casualty Department on 17 March 1992 with a localised area of redness on the medial aspect of the left globe. This initially responded to topical betamethasone and neomycin drops. However, it recurred and he reattended 3 weeks later, when he was noted to have a conjunctival mass at the same site, with a firm mass palpable in the superonasal quadrant of the left orbit. He was referred to Outpatients, and was seen on 14 April.

His vision was $6 / 9$ aided, in each eye. There was a very firm mass in the superonasal quadrant of the left orbit, dis-

From: 'Department of Ophthalmology, University Hospital, Nottingham; ${ }^{2}$ Department of Oncology, General Hospital, Nottingham, UK.

Correspondence to: Mr C. E. Hugkulstone, FRCSEd, FRCOphth, Department of Ophthalmology, University Hospital, Nottingham NG7 2UH, UK.

Eye (1994) 8, 580-582 C 1994 Royal College of Ophthalmologists placing the globe inferotemporally (Fig. 1). Ocular movements demonstrated limitation of abduction, adduction and elevation of both eyes, more marked on the left, associated with diplopia. There was a fleshy lesion on the medial aspect of the left globe (Fig. 2). Pupil reactions were normal. The left disc appeared healthy but the right was hyperaemic with some choroidal folds over the posterior pole. Results of a full blood count, urea and electrolyte measurements, and liver and thyroid function tests were within normal limits. An orbital CT scan was performed 10 days later and revealed an intraconal mass in the right orbit and an extraconal mass placed anteriorly and medially in the left orbit, displacing the globe laterally and inferiorly (Fig. 3).

Synchronous with his ophthalmic presentation, the patient was seen by the Urology Department on 24 March with a 1 month history of painless haematuria. On 15 April he was admitted by them as an emergency with cellulitis over enlarged inguinal lymph nodes. The cellulitis responded to systemic antibiotics, although the lymphadenopathy remained. An abdominal CT scan revealed a mass in the right lateral wall of the bladder. No other abnormalities were noted. One week after admission, cystoscopy was performed and a biopsy was taken from an unusual oedematous area on the right side of the bladder. Histology revealed this to be poorly differentiated TCC, which was deeply invasive.

Because of the high likelihood of there being two separate primary tumours (particularly a non-Hodgkin's lymphoma as well as the bladder tumour), biopsy of the left orbital mass and the right inguinal lymph nodes was undertaken on 20 May. Histological examination revealed both specimens to be infiltrated by metastatic carcimona, in keeping with a transitional cell primary in the bladder.

Initial management of this widely disseminated TCC of the bladder was with methotrexate, vinblastine, mitozantrone and carboplatin. This failed to control the tumour. Local radiotherapy was also ineffective, and the patient died of metastatic cancer 5 months after presentation. 


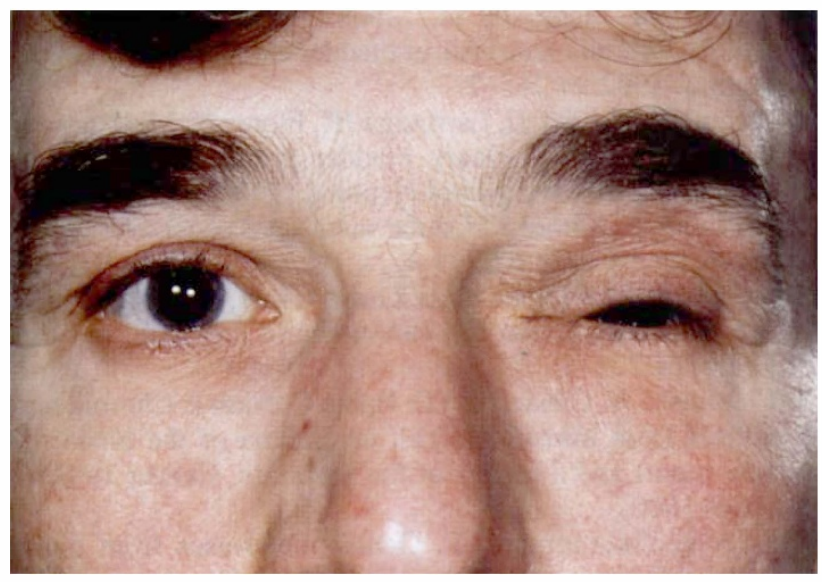

Fig. 1. Left orbital mass visible in the superonasal quadrant.

\section{DISCUSSION}

Transitional cell carcinoma of the bladder rarely involves the ophthalmologist. There are only three recorded cases of orbital involvement: two histologically verified ${ }^{8.9}$ and one in a man with a 'retro-orbital metastatic mass' on CT scanning, who had required radical cystectomy 11 months earlier. ${ }^{10}$ There are a further five reports of choroidal metastases: three from tumours arising in the bladder ${ }^{11-13}$ and two from elsewhere in the urinary tract. ${ }^{1+.15}$ In a study of ocular and orbital metastases from primary carcinoma, Font and Ferry ${ }^{6}$ found a ratio of $7: 1$ for ocular to orbital involvement.

Compared with the three previous reports of orbital metastases from TCC of the bladder, ${ }^{8-10}$ our patient was considerably younger. He presented with symptoms and signs of both the primary tumour and the orbital metastases almost simultaneously. Only one of the previous reports ${ }^{8}$ had a similar presentation, whilst the other two cases had an interval of several months between diagnosis of the primary tumour and the onset of orbital metastases. ${ }^{9.10}$ This is the more usual course of events with metastases to the orbit, ${ }^{5}$ although Font and Ferry ${ }^{6}$ found one case in their report of 28 orbital metastases with symptoms of the primary tumour and of the orbital metastases occurring at the same time. However, presentation of orbital metastases before identifying the primary tumour is also

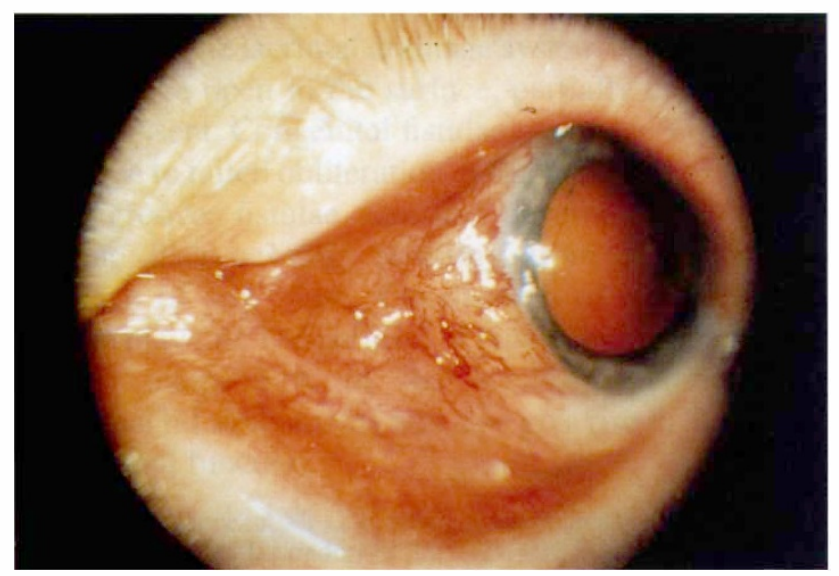

Fig. 2. Lesion on the medial aspect of the left globe.

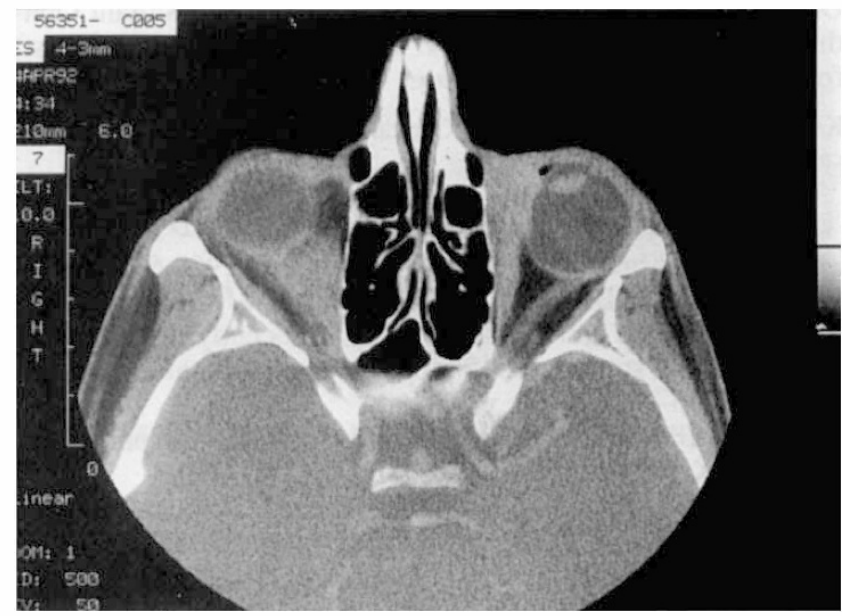

Fig. 3. Orbital CT scan, showing anteriorly placed mass medially in the left orbit and an intraconal mass in the right orbit.

recognised, occurring in between $24 \%{ }^{5}$ and $61 \%{ }^{6}$ of reports.

The other point of interest is the presence of bilateral orbital metastases in our patient. The previous reports of orbital metastases from TCC of the bladder were unilateral in all three cases. ${ }^{8-10}$ In series where the laterality of orbital metastases was recorded, bilateral lesions were found in $0,{ }^{1} 7 \%,{ }^{6} 8 \%$ and $21 \%$. $^{7}$ The diagnoses of bilateral orbital tumours (metastatic and other), where given, ${ }^{1.5 .7}$ are shown in Table I, with breast being the commonest primary tumour.

Deep muscle invasion by TCC of the bladder (as in our case) carries a poor prognosis, with a high probability of dying of bladder cancer. ${ }^{16}$ Although there do not appear to be any reports of metastases as the initial presentation of this stage of TCC, between $29 \%^{17}$ and $50 \%^{16}$ of such patients develop metastases within 2 years of diagnosis. The commonest sites for distant metastases of bladder TCC are lymph nodes (88\%), liver (51\%), lungs (39\%), bones $(22 \%)$ and peritoneum $(13 \%))^{16}$

In conclusion, this case serves to emphasise the rarity of metastatic orbital tumours from a primary TCC in the bladder. These patients seem to have a poor prognosis, with two of the previous reports recording death within 1 month of diagnosis. ${ }^{9.10}$ Similarly, choroidal metastases from TCC also have a poor outlook. ${ }^{13.15}$

Table I. Diagnosis of bilateral orbital tumours

\begin{tabular}{lcc}
\hline Diagnosis & Number & Percentage \\
\hline Breast primary & 7 & 20.6 \\
Mucocoele & 6 & 17.7 \\
Extension of retinoblastoma & 6 & 17.7 \\
Endocrine & 3 & 8.8 \\
Lymphangioma & 3 & 8.8 \\
Pseudotumour & 1 & 2.9 \\
Osteoma & 1 & 2.9 \\
GI tract primary & 1 & 2.9 \\
Cutaneous melanoma & 1 & 2.9 \\
Miscellaneous & 3 & 8.8 \\
Unknown primary & 2 & 5.9 \\
Total & 34 & 99.9 \\
\hline
\end{tabular}

From Silva,' Goldberg and Rootman ${ }^{5}$ and Freedman and Folk. ${ }^{7}$ GI, gastrointestinal. 
Our grateful thanks are due to Mr S. N. Rizk (Consultant Ophthalmic Surgeon) and Mr M. A. Taylor (Consultant Urologist) for permission to report this case.

Key words: Bilateral, Bladder, Orbital metastases, Transitional cell carcinoma.

\section{REFERENCES}

1. Silva D. Orbital tumors. Am J Ophthalmol 1968;65:318-39.

2. Shields JA, Bakewell B, Augsburger JJ, Flanagan JC. Classification and incidence of space-occupying lesions of the orbit: a survey of 645 biopsies. Arch Ophthalmol 1984; 102:1606-11.

3. Reese AB. Expanding lesions of the orbit. Trans Ophthalmol Soc UK 1971;91:85-104.

4. Moss HM. Expanding lesions of the orbit: a clinical study of 230 consecutive cases. Am J Ophthalmol 1962;54:761-70.

5. Goldberg RA, Rootman J. Clinical characteristics of metastatic orbital tumors. Ophthalmology 1990;97:620-4.

6. Font RL, Ferry AP. Carcinoma metastatic to the eye and orbit. III. A clinicopathologic study of 28 cases metastatic to the orbit. Cancer 1976;38:1326-35.

7. Freedman MI, Folk JC. Metastatic tumors to the eye and orbit: patient survival and clinical characteristics. Arch Ophthalmol 1987;105:1215-19.

8. Smiley SS. An orbital metastatis from the urinary bladder. Arch Ophthalmol 1965;74:809-10.
9. Krauss HR, Slamovits TL, Sibony PA, Dekker A, Kennerdell JS. Orbital metastasis of bladder carcinoma. Am J Ophthalmol 1982;94:265-7.

10. Angulo JC, Lopez JI, Larrinaga JR, Flores N. Metastasising carcinoma of the urinary bladder presenting as a retroorbital mass. Scand J Urol Nephrol 1991;25:83-4.

11. Gordon HL, Munro R. Ocular metastasis of bladder cancer. South Med J 1974;67:745-6.

12. Resnick MI, O'Conor VJ Jr, Grayhack JT. Metastases to the eye from transitional cell carcinoma of the bladder. J Urol 1975; 114:722-4.

13. Cieplinski W, Ciesielski TE, Haine C, Nieh P. Choroid metastases from transitional cell carcinoma of the bladder: a case report and a review of the literature. Cancer 1982;50: 1596-1600.

14. Pe'er J, Zimmerman LE. Ocular metastases from transitional cell carcinoma of the urinary tract. Graefes Arch Clin Exp Ophthalmol 1984;221:137-41.

15. Atta HR. Presumed metastatic transitional cell carcinoma of the choroids. Br J Ophthalmol 1983;67:830-3.

16. Pode D, Fair WR. The biology of urothelial tumors. In: Chisholm GD, Fair WR, editors. Scientific foundations of urology. 3rd ed. Oxford: Heinemann Medical Books, 1990: 582-9.

17. Prout GR Jr, Griffin PP, Shipley WU. Bladder carcinoma as a systemic disease. Cancer 1979;43:2532-9. 